\title{
Digital marketing and the potential for financial growth of small and medium-sized businesses
}

\author{
Mila Mitreva1, Monika Arsova² Tamara Jovanov Apasieva ${ }^{3}$ \\ ${ }^{1}$ Goce Delcev University, Faculty of Economics, e-mail: mila.mitreva@ugd.edu.mk \\ ${ }^{2}$ Goce Delcev University, Faculty of Economics, e-mail: monika.arsova@ugd.edu.mk \\ ${ }^{3}$ Goce Delcev University, Faculty of Economics, e-mail: tamara.jovanov@ugd.edu.mk
}

\begin{abstract}
The aim of this paper is to provide better understanding of the meaning and the importance of digital marketing. Considering that large organizations are usually of interest when it comes to developing and analyzing marketing theory, this paper focuses on the SMEs. Marketing practices differ between large and small companies, which is the reason why better understanding of marketing practices and marketing planning can help the SMEs in increasing their performance. Hence, small businesses usually lack financial and human resources, which is why digital marketing can help them in better satisfying the needs of the targeted market and to be more efficient than the competitors. Consequently, implementation of the adequate marketing techniques can enhance the success and financial growth of the SMEs.
\end{abstract}

Kev words: digital marketing, SME, growth, performance, strategy

\section{Introduction}

For every business entity that wants to maintain long-term success, the customers have to represent the most important asset. Those companies who have recognized this importance should continuously work on implementing methods that will help them in the process of customer acquisition, retention and development. However, this process requires adequate and improved marketing decisions and better marketing accountability [1]. Digital marketing, which firstly developed as a subtype of conventional marketing, nowadays represent a new phenomenon that accomplishes the marketing goals through various tools and strategies. The benefits and the potential for brands and organizations that digital marketing brings are the branding, completeness, functionality, visual communication, community connections and vitality. Hence, following up the strategy and the goals of the company, implementing an adequate digital marketing plan can help the organizations to achieve their mission, vision and values [2]. Therefore, businesses can use various digital channels, such as social media, email, websites and different online platforms that can help them in connecting with their current 
and the potential customers. However, considering that almost every person spends much of their time online, digital tools can increase the ability of the companies not only to attract the customers, but also to build trust with the customer, impact their emotional level and consequently achieve financial gains. Nevertheless, for obtaining greater impact and achieving financial success, strategic approaches and tactical marketing decisions have to be implemented. Existing literature confirms that customer retention has positive impact on shareholder value [1]. However, determining the financial benefit of the marketing activities can be critical topic. Moreover, the marketing activities that are implemented by the companies serve as a competition tool through which businesses try to persuade the potential customers in choosing their product or service. Therefore, marketing activities serve as a major driver of a company's performance and aim to protect the shareholders' interests. Nevertheless, in this competitive corporate world the marketing activities have dual effect. On one hand, they contribute to achieving financial benefits, and on the other they bring marketing benefits, such as customer satisfaction [3]. Therefore, the aim of this paper is to analyze the impact that digital marketing has on the financial growth of small businesses.

\section{Importance of digital marketing}

Digital marketing refers to the process of promoting a brand, service or product on the internet through the usage of online channels and methods [4]. The availability of statistical data regarding the consumers' behavior, their interests and demographics have contributed to the rapid development of digital marketing. It is worth mentioning that the organization's marketing objectives determine the nature of digital marketing method. The marketing strategy that will be implemented depends on the goal that the company wants to achieve, which can be increasing the sales, building the brand image or the brand engagement. Therefore, digital marketing has very important role in marketing research and practice activities of many organizations around the world [4]. This is an important concept because it helps the organizations to build lasting customer relationships. It is worth mentioning that nowadays the universal access to internet, the advanced technologies and the mobile gadgets widen the possibilities through which the companies can identify the customers' needs and attract their attention.

\subsection{Digital marketing and B2B}

Studying the digital marketing in the business-to-business (B2B) sector has not been the focus for many scholars, compared to the areas that are more deeply analyzed, such as online retailing, advertising, branding, gamification etc. According to Kannan (2017) the development in digitalization has increased the interest for B2B relationships [5]. This is due to the fact that digitalization has reshaped the ways in which companies offer their product/service and the way in which the customers behave. According to Hofacker, et al. (2020), artificial intelligence, block chain, data security, data analytics are some of the factors that affect the way in which B2B relationships are handled [4]. Grewal et al. (2015) in his paper highlights the differences that exist in the channels of digital marketing communication between the developing and the developed countries [6]. Nevertheless, almost every person around the globe uses internet, which makes the adoption of digital marketing techniques a necessity. In this context Alavi 
(2016) claims that the difference that exists between the developed and the developing countries regarding the rate of internet usage, can deeply affect the companies' adoption of B2B digital strategies [7]. It is also worth mentioning that the emerging economies are characterized by much less B2B platforms for e-commerce compared to the developed economies, as well as low level of customer usage and high offline buying activities. Furthermore, lower level of internet usage and low PC penetration are some of the factors that contribute to the firms in the developing countries to have more e-business challenges than the companies in the developed countries. The increasing rate of mobile phone usage of $\mathrm{B} 2 \mathrm{~B}$ applications contributes to the outgrowing level of B2B digital marketing over the B2C ebusiness. Finally yet importantly, digital marketing helps the businesses to create and maintain a relationship with the existing clients, to attract new customers and to positively affect on every current and potential buyer [8].

\subsection{Digital marketing and B2C}

The traditional marketing channels are being much less used, and the digital marketing is the new revolution in the field of marketing that started to reshape the ways in which companies interact with the clients. Nevertheless, digital marketing includes several processes and various strategies can be used in order to attract an audience online. Some of those strategies include search engine optimization (SEO), Pay per click (PPC) advertising, social media advertising, web design and development, content marketing and e-mail marketing. SEO is a part of inbound marketing, which refers to the company being found by the customers, contrary to the outbound marketing where the company finds the customers. SEO is considered a longterm strategy, where user-friendly URL structure, relevant titles, clear domain name and structured source code are a necessity. However, considering that this is a long-term strategy in order to achieve success, the company should also implement short-term strategy [9]. Furthermore, the search engine marketing is consisted of Paid and Organic Search. Google has algorithm that provides the most relevant organic results, whereas, the Pay per click (PPC) advertising shows the sponsored results together with the original ones. PPC is considered a strategic communication tool on the Internet because it provided the companies a better position on search result pages. Hence, SEO and PPC advertising are both part of the search engine marketing (SEM) and both help the companies to create brand awareness, familiarity, and favorable content. Considering their benefits, online marketing is one of the most important revenue source for search engine companies such as Google, Bing, Yahoo etc. [10]. Furthermore, the rise of social media created opportunities for both the companies and the consumers. The rapidly changing communication environment provides many opportunities, as well as challenges for the businesses, especially those that are small. Nevertheless, social media is a revolutionary tool through which people from every generation can be affected and companies can more easily understand the consumers' behavior, preferences and purchase decisions. With this understanding, they can affect the decision-making process and can influence the opinions and the attitude formation of the customers. Therefore, developing the right marketing strategy through this tool can provide great financial benefits for the companies [11]. However, the common thing for all of the strategies is that the aim of $\mathrm{B} 2 \mathrm{C}$ digital marketing is to develop deep relationships with the clients, thus, they will always come back and purchase repeatedly.

\subsection{Digital marketing trends}

In Graph 1 are presented the most effective digital marketing techniques according to marketers worldwide in 2021. According to the obtained results, content marketing was 
believed to be the most effective digital technique in 2020 (17.4\%), followed by marketing automation (17.4), big data (15.3\%), artificial intelligence and machine learning (12.9\%), social media marketing (7.8\%), conversion rate optimization (CRO) $(4.8 \%)$, communities $(4.8 \%)$, paid search marketing (3.9\%), mobile marketing (3\%), SEO (3\%) and partnership and display were least used (2.7\%) [12].

Graph 1: Most effective digital marketing techniques according to marketers worldwide in 2020

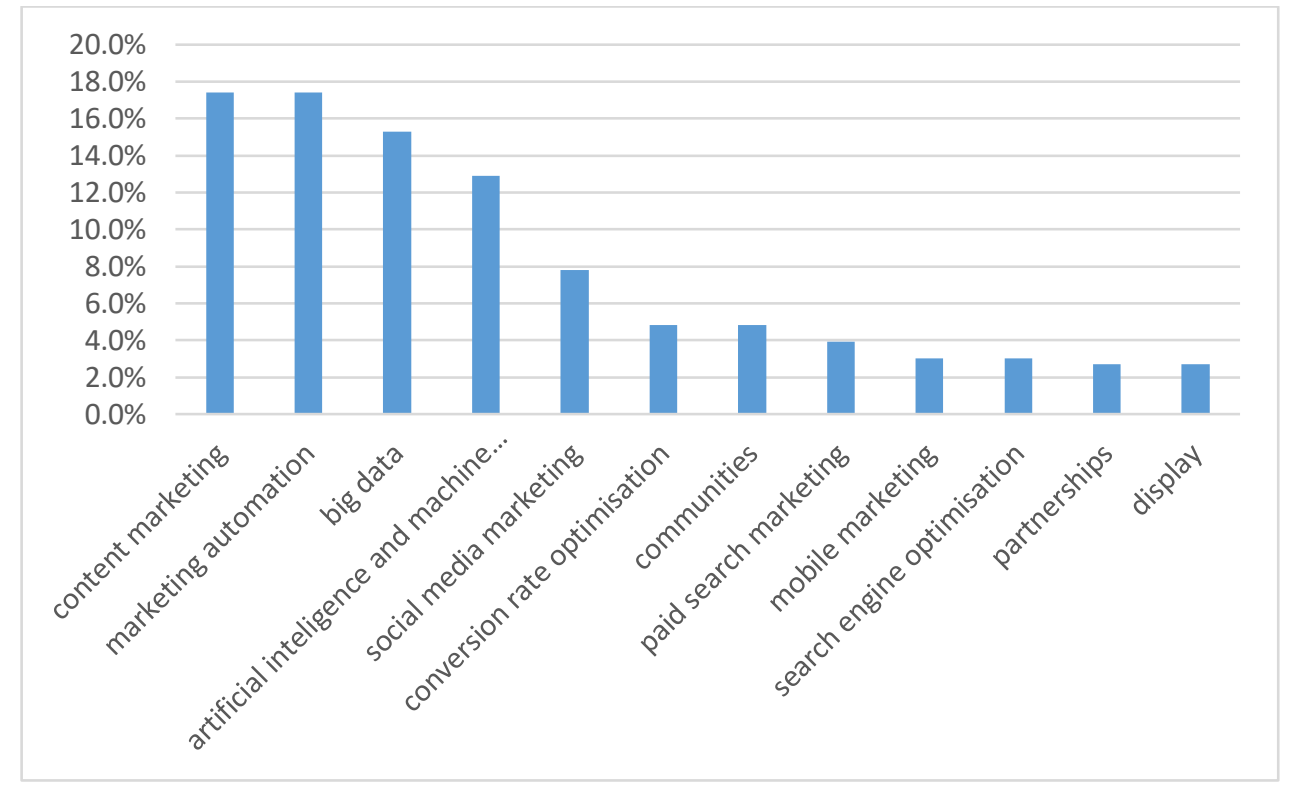

Source: Statista (2022) [12]

Regarding the presented results, an explanation why content marketing was mostly used may be the fact that customers live in an age of information abundance. Therefore, marketers are faced with the challenge on finding the right channel through which will influence the targeted audience. Hence, content marketing serve as the linking fuel for customer engagement, because it is a process for creating valuable and relevant content in order to attract customers and engage with the audience [13]. Furthermore, marketing automation was ranked the same as the content marketing and it is considered an effective digital marketing technique. The goal of this technique is to automate repetitive marketing tasks by a range of media such as e-mail, webinars, social media etc. Its main capabilities include maintaining databases of customers, analysis of customer behavior, monitoring of B2B visits etc. To sum up, marketing automation has many functionalities, with the main activity to monitor and track the behavior of the existing and the potential clients [14]. The third most effective digital marketing technique is "Big data". The massive use of internet and the development of new technologies contributed to creation of digital data. This data availability is of great importance for companies because based on that they can make right decision and implement the adequate strategies. The increasingly complex volumes of data can also represent a challenge because they are continuously growing. Therefore, Big Data, which is a set of technologies and techniques, serves as a solution because it provides real-time access to those huge databases. Hence, it solves the problems in much better and more effective way [15].

\section{Impact of digital marketing on small businesses}


As mentioned above, digital marketing is the marketing conducted on digital platforms. Literature shows that the use of various digital marketing techniques can help small businesses to increase their customer pool, create an online brand, increase their brand awareness and more profoundly connect with the customers. Some of the justifications why digital marketing is the right marketing strategy lies in its cost-effectiveness, because it consumes less capital compared to the traditional marketing methods. Thus, the lower usage of capital is of great assistance to the small companies because of the higher conversion rate. Consequently, higher conversion rates lead to increased revenues and through the right digital marketing tactics, small businesses can stand well in competition. To sum up, the main benefits of digital marketing for small businesses include reaching for a global audience, targeting the right audience, driving engagement with the customers and creating brand loyalty [16]. However, the literature shows that the benefits of digital marketing are well known, but the usage of digital marketing by small businesses is something that is not so well analyzed. This is because the digital marketing literature focuses mostly on larger businesses and organizations [17]. The financial constraint is the main factor that limits the small businesses to invest in digital marketing. Nevertheless, the amount of investment in this field mostly depends on the existing marketing strategy of the company and its expectation for success [18]. Nguyen et al. (2015) claim that the digital footprint and the speed of the technology adoption differentiates between small and large businesses. Small businesses usually implement "learn by doing it yourself" method and through the process of self-learning, they learn how to build relationships with customers [19].

Small and medium sized businesses are the driving force for economic growth, innovation and social integration. They employ most of the population, but the main challenges they face are difficult access to finance, poor integration in the global supply chains and challenging regulatory environments. Hence, the financial burden that they face limits their ability for expansion and much less investing in marketing. Therefore, in the paper of Jovanov, et al. (2019), most of the firms have selective approach to marketing activities [20]. Additionally, in another paper it was estimated that the implementation of integrated communication results affect positively the financial performance of the companies [21]. Undoubtedly, people nowadays live in digitalized world, where the traditional ways of interacting are starting to vanish. The digitalization will continue to reshape the way in which firms conduct their activities, transfer their message to the customers and attract new customers. This transformation will change the consumer behavior and it will have consequences for both producers and the consumers. However, research also shows that the SMEs are not very effective in utilizing the digital tools and they are more focused on overcoming their challenges, such as profitability and growth [22]. Nevertheless, the various digital channels that developed in the past several years have been viable channel for small businesses through which they will attract and retain the customers. Not only that these channels help the smaller businesses to more easily and directly communicate with the customers, they also assist them in increasing their revenues, and sustaining their business. Digital marketing is useful for the SMEs because it provides them with global reach of the customers, it makes them more able in targeting their customers and contributes to an increased market share and profitability [22]. Considering that small business do not have the budget for marketing such as large firms, almost every SME has moved to more affordable and interactive marketing, such as digital marketing. In this context, they have more opportunities and are more flexible and innovative in the process of communicating with the customers compared to the larger companies [22]. 


\subsection{SMEs and their marketing practices}

Theory shows that for the growth and development of the SMEs, marketing function plays crucial role and the marketing practices mostly depend on the experience in marketing of the manager or the owner [23]. Bettiol, et al. (2012) in their paper obtained similar conclusion that the managers of the SMEs are factor that contributes to the creation and the implementation of the marketing strategies [24]. The business environment constantly develops and efficiency and flexibility are required from the companies in order to boost their business performance. Hence, the business environment and the competition have enormous impact on the performance of the SMEs, where Clark (2001) in his paper claims that for understanding the market and being innovative, marketing is essential [25]. However, the marketing practices of the small companies are influenced by many factors, such as limited resources, competitors, the business environment in general and the inherent skills of the manager. These factors characterize the marketing of the SMEs as haphazard, unstructured and informal [26]. Nevertheless, the globalization and digitalization have also affected the marketing practices of many companies.

\section{Conclusion}

The business world and the market are functioning in a digitalized era, where the competition is fierce and the opportunities are unlimited. Keeping up with all the available information and providing the products or services that will satisfy the customers' needs, as well as achieving profit can be very challenging for small businesses. Therefore, for optimizing the actions of a company, digital marketing can help in many ways. It assists the businesses in delivering the right information to the audience, easily attracting customers and increasing their sales. The requirements of the consumers are constantly evolving, thus, companies need to implement flexible and adaptable, cost efficient strategies. Hence, digital marketing has proven to be very important for SMEs that want to increase their productivity and profitability and create competitive position. However, theory showed that the financial ability of the SMEs plays very important role in their marketing decisions. Not only the financial resources, but also the human resources are important for the development of marketing strategies of the SMEs. These companies lack understanding of the marketing principles, and the marketing decisions are mostly made by the managers. Therefore, assistance from external experts or government support can be factors that may help the SMEs to better understand the marketing principles, to find more efficient and faster way in adapting to the changes in the market and to provide products/services that are required by the consumers. Consequently, better marketing education and financial resources assistance will contribute to better financial performance of the SMEs and increased presence in the market. Finally yet importantly, long term and stable growth is created from the decisions made in the present. Adequate marketing activities contribute to increased sales and create opportunities for keeping up with the changes in the market. Notwithstanding, small and medium sized businesses should focus on utilizing the most suitable for them marketing technique in order to be competitive. Hence, digital marketing can serve as the most cost-efficient way through which these companies can achieve success. 


\section{References:}

[1] Wiesel, T., et al. (2008) Customer equity-an integral part of financial reporting. Journal of Marketing. Vol. 72, p. 1-14.

[2] Machado, C. \& Davim, J. P. (2016) "Understanding Digital Marketing-Basics and Actions". Management and Industrial Engineering.

[3] Mousa, M., et al. (2021) The effect of marketing investment on firm value and systematic risk. Journal of Open Innovation: Technology, Market and Complexity. Vol. 7, No. 64, p. 1-17.

[4] Hofacker, C. F., et al. (2020) "Digital marketing and business-to-business relationship: a close look at the interface and roadmap for the future", European Journal of Marketing.

[5] Kannan, P. (2017) "Digital marketing: A framework, review and research agenda", International Journal of Research in Marketing, Vol. 34, No. 1, p. 22-45.

[6] Grewal, R., et al. (2015) "Business-to-business buying: Challenges and opportunities", Customer Needs and Solutions, Vol. 2, No. 3, p. 193-208.

[7] Alavi, S. (2016) "New paradigm of digital marketing in emerging markets: From social media to social customer relationship management", International Journal of Management Practice, Vol. 9, No. 1, p. $56-73$.

[8] Almeida, M. S. and Agnihotri, R. (2019) "In pursuit of an effective B2B digital marketing strategy in an emerging market", Journal of the Academy of Marketing Science.

[9] Zilincan, J. "Search engine optimization". CBU International Conference on Innovation, Technology, Transfer and Education.

[10] Khraim, H. (2015) "The effects of using Pay per click advertisement on online advertisement effectiveness and attracting customers on E-marketing companies in Jordan", International Journal of Marketing Studies, Vol. 7, No. 1, p. 180-189.

[11] Rahman, M. M. (2018) "Social media advertising responses and its effectiveness: case of South Asian Teenage Customers" Global Journal of Management and Business Research, Vol. 18, No. 4.

[12] Statista (2022) "Most effective digital marketing techniques according to marketers worldwide in 2020", Statista website. Retrieved from: https://www. statista.com/statistics/190858/most-effectiveonline-marketing-channels-according-to-us-companies/

[13] Jones, M. (2021) "Engaging content marketing”, Marketo website. Retrieved from: https://go.marketo.com/rs/marketob2/images/DG2ECM.pdf

[14] Swieczak, W. (2013) "Marketing automation processes as a way to improve contemporary marketing of a company". Institute of aviation, Warsaw, Poland.

[15] Riahi, Y. and Riahi, S. (2018) "Big data and big data analytics: concepts, types and technologies", International Journal of Research and Engineering, Vol. 5, No. 9, p. 524-528.

[16] Ertugrul, T. U. (2021) "Impact of digital marketing on small businesses in 2022", Dan Institute. Retrieved from: https://daninstitute.com/blog/impact-of-digital-marketing-on-small-businesses/

[17] Michaelidou, N., Siamagka, N.T. and Christodoulides, G. (2011), "Usage, barriers and measurement of social media marketing: an exploratory investigation of small and medium B2B brands", Industrial Marketing Management, Vol. 40 No. 7, p. 1153-1159

[18] Reichheld, F.F. and Schefter, P. (2000), "E-loyalty: your secret weapon on the web", Harvard Business Review, Vol. 78 No. 4, p. 105-113.

[19] Nguyen, T.H., Newby, M. and Macaulay, M.J. (2015), "Information technology adoption in small business: confirmation of a proposed framework", Journal of Small Business Management, Vol. 53 No. 1, pp. 207-227. 
[20] Jovanov, T., et al. (2019) "Make it happen: marketing processes for competitive market positioning of firms in transitional economy". Eurasian Business Perspectives, Eurasian Studies in Business and Economics 10/1, Vol. 10, No. 1, p. 387-406.

[21] Jovanov, T., et al. (2017) "Impact of integrated communication on entrepreneurial companies' financial performance - A developing economy". Financial Environment and Business Development, Vol. 4, p. 29-41.

[22] Fasasi, L. (2017) “Effect of digital marketing on firm's financial performance". Obafemi Awolowo University, Nigeria.

[23] Akingbade, W. A., et al. (2013) "Marketing practice of small and medium enterprises (SMEs) perspective from a developing country" Mediterranenan Journal of Soocial Sciences. Vol. 4, No. 3, p. 243-258.

[24] Bettiol, M., et al. (2012) "Marketing in SMEs: the role of entrepreneurial sensemaking". International Entrepreneurship and Management Journal, Vol. 8, Issue 2, p. 223-248.

[25] Clark, B.H. and Ambler, T. (2001) "Marketing performance measurement: evolution of research and practice". International Journal of Business Performance Management, Vol. 3, No. 2-4, pp. 231244.

[26] Gilmore, A., et al. (2001) "SME marketing in practice". Marketing Intelligence \& Planning, Vol. 19, No. 1, p. 6-11. 